\title{
The Effect of Illness Representations on Health- Related Quality of Life (HRQoL) in Obesity: The Role of Coping Strategies as Mediator
}

\author{
Marfu' $^{\prime} h^{1}, *$, Grestin Sandy ${ }^{2}$, Mayenrisari Arifin ${ }^{3}$
}

\author{
${ }^{1}$ Psychology Department, Medical Faculty, Hasanuddin University \\ ${ }^{2}$ Psychology Department, Medical Faculty, Hasanuddin University \\ ${ }^{3}$ Psychology Department, Medical Faculty, Hasanuddin University \\ *Corresponding author. Email: marfuahrahman7@gmail.com
}

\begin{abstract}
Obesity is a health problem with characteristics and symptoms that can be easily recognized. Nevertheless, awareness of obesity as a threat is far less, even if the risk factors can lead to more chronic diseases. This shows the importance of howpeople perceive obesity to minimize the impact of obesity itself. This study aims to examine the effect of illness representations on health-related quality of life and see the role of coping strategies as a mediator in the effect of illness representations on health-related quality of life (HRQoL) in obesity. This study uses a quantitative approach with non-experimental quantitative research. The sample ofthis study was 44 people with obesity. The instruments used in this study to measureillness representations were B-IPQ, to measure HRQoL was WHOQOL-BREF, and to measure coping strategies was BRIEF COPE. The data in this study were analyzed with simple regression and path analysis. The finding in this study shows a negative impact of illness representationson HRQoL in obesity with $22,8 \%$ impact values. This impact was not mediatedby coping strategies, either approach or avoidant coping. Nevertheless, this study found that independently coping strategies impact HRQoL. Approach coping has a positive impact on HRQoL, while avoidant coping has a negative impact on HRQoL.
\end{abstract}

Keywords: Illness representations, health-related quality of life, coping strategies, obesity

\section{INTRODUCTION}

World Health Organization[1] states that in 2016 there were $39 \%$ of individuals were overweight, and $18 \%$ of them were obese. Based on the 2018 Basic Health Research Results, it was found that the prevalence of overweight and obesity increased from $14.8 \%$ (in 2017) to $21.8 \%$ and became the first noncommunicable disease in Indonesia[2]. The increasing prevalence of obesity has become one of the important health problems to be considered in the future, especially in obese people themselves. In addition, overweight and obese individuals need to make their situation more seriously and anticipate various health threats associated with obesity conditions such as hypertension, dyslipidemia, diabetes, and other cardiovascular diseases[3]. This shows that obese people need to better understand and perceive their situation as a condition that can threaten their health to take appropriate treatment actions for their condition.
The implications of obesity are on physical health and have significant implications for the quality of life of individuals [4]. Broadly, this quality of life describes physical health, psychological state, level of independence, social relationships, personal beliefs, and individual relationships with their environment[5] —also known as health-related quality of life (HRQoL). Several conditions that affect the decrease in quality of life in obese people are bodyweight, health-related issues experienced, perceptions, and feelings of the stigma that individuals receive[6][7][8]. This condition can worsen if the underlying conditions cannot be immediately treated and the cause is not found. This should matter because it is found that individual perceptions and feelings regarding the obesity condition they suffer significantly affect the obesity condition experienced by the patient. These perceptions and feelings of illness individuals suffer known as illness representations[9]. 
Illness representations can be an important factor in predicting an individual's quality of life[9]. Based on the Common Sense Model of Self-Regulation, when individuals perceive a threat (either physical symptoms or changes in function), they will develop representations called illness representations that will direct them to perform coping strategies against the illness they are suffering from[10]. When individuals have implemented coping strategies, individuals will evaluate the coping strategies that have been carried out in various forms, including the individual's quality of life[11]. The way individuals perceive illness and how individuals deal with it (coping) can affect the quality of life of individuals both physically and mentally[12].

In obese patients, it was found that individual illness representations did not directly affect an individual's HRQoL. Before arriving at the HRQoL evaluation, the form of action or coping strategies applied - such as diet, physical activity, medication, emotional involvement-had a significant role in increasing and decreasing an individual's HRQoL. Obesity is a disease that is suffered due to an unhealthy lifestyle. Therefore, various forms of coping strategies that individuals can apply to overcome this situation can also be obtained through lifestyle changes such as diet or exercise and doing physical activity or shedding through emotional feelings[13][14][15]. This further strengthens that the individual's representation of the disease can influence the applied coping strategies to affect the individual's HRQoL changes. Therefore, this study aims to find a more in-depth explanation of the effect of illness representations on HRQoL in obese patients, using coping strategies as a mediator.

\section{METHOD}

\subsection{Participant}

This study was conducted on obese patients with BMI over $25.1 \mathrm{~kg} / \mathrm{m} 2$ (based on the obesity category in Indonesia) who have been obese for at least two weeks. The obese patients in this study were in adulthood in 20 to 40 years $(n=44)$. Each participant was given a questionnaire online and offline (following the health protocol) that measured illness representations, coping strategies, and individual HRQoL using the purposive sampling technique.

\subsection{Measurements}

\subsubsection{Dependent Variable}

WHOQOL-BREF was used to measure HRQoL as the dependent variable. This instrument was developed by WHO[16] and adapted into Indonesian by Renaldi[17]. This instrument contains 26 items, namely two items to measure the overall quality of life and the other 24 items measuring the four domains, which are physical health (7 items), psychological (6 items), social relationships ( 3 items), and environment (8 items). This instrument shows a CFI value of 0.640 and a reliability coefficient of Cronbach's alpha of 0.808 (strong reliability).

\subsubsection{Independent Variable}

The Brief Illness Perception Questionnaire (BIPQ) was used to measure illness representations as an independent variable. This instrument was developed by Broadbent et al.,[18] from the Illness Perception Questionnaire (IPQ) by Moss-Morris et al.,[19] and has been adapted into Indonesian by Indrayana and Fang[20]. This instrument contains nine items, with eight items in the form of a Likert scale (which measures one aspect each) and one item, an openended question to measure causal or the cause of the disease. Every item is grouped into three groups, namely cognitive (consequence, timeline, personal control, and identity), emotional (illness concern and emotional representations), and comprehensibility (illness coherence). This instrument shows a CFI value of 0.826 and a reliability coefficient of Cronbach's alpha of 0.516 (moderate reliability).

\subsubsection{Mediator}

Brief Coping Orientation to Problem Experienced (Brief COPE) was used to measure coping strategies as a mediator variable. This instrument was developed by Carver [21]. This instrument contains 28 items which are divided into two groups, that are approach coping (active coping, planning, positive reframing, and acceptance) and avoidant coping (using emotional support, using instrumental support, self-distraction, denial, venting, substance use, behavioral disengagement, and self-blame). Two items measure each aspect. This instrument shows a CFI value of 0.685 (approach coping) and 0.569 (avoidant coping), and the reliability coefficient of Cronbach's alpha is 0.758 (reliable enough). 


\subsection{Statistical Analysis}

The data in this study were analyzed using the Statistical Package for Social Sciences (SPSS) version 23 and AMOS version 25. As for measuring the effect between variables, path analysis methods were used using simple regression and multiple regression. In this analysis model, path coefficients are used to predict the process on the existing path[22]. The mediator variable analysis uses two independent variable roles: direct and indirect effects. The sum of the two lines of roles is called the total role[23]. The mediator variable plays an effective role when in the total role, the portion of the indirect role pathway is greater than the direct role pathway[24]. Therefore, in this study, the analysis will be carried out in two stages. The first is to see the direct influence between illness representations and HRQoL. The second is to see the effect of illness representations on HRQoL with coping strategies as a mediator.

\section{RESULT}

\subsection{Descriptive Statistics}

Table 1 shows that the participants of this study were dominated by women $(61 \%)$, single $(80 \%)$, and severely obese patients with BMI > 27.0 (82\%) or Obese II. Based on Table 1, it was also found that the three most common causes of obesity perceived by participants were eating style $(91 \%)$, sleep patterns $(55 \%)$, and lifestyle $(52 \%)$. In addition, it was found that half of the participants $(50 \%)$ could not be described in the form of coping strategies used to deal with obesity, while $30 \%$ of other participants used approach coping and the other $20 \%$ used avoidant coping.

\subsection{Simple Regression}

Table 2 describes the results of the regression analysis of the influence of illness representations on HRQoL, which shows that there is an effect of illness representations on HRQoL $(p=0.001 ; p<0.05)$ with a negative effect $(\beta=-0.85)$. This shows that the higher the illness representations score, the lower the individual's HRQoL. These results explain that the more threatening obesity is perceived by individuals, the lower the individual's quality of life. The influence of illness representations on HRQoL is $22.8 \%(\mathrm{R} 2=$ 0.228).
In addition, it was found that the only dimension of illness representations that affect each HRQoL dimension is the comprehensibility dimension, while other dimensions of illness representations, cognitive and emotional, do not have any influence on each HRQoL dimension. The influence of the comprehensibility dimension on all HRQoL is negative. This shows that the higher comprehensibility, the lower HRQoL of the individuals.

\subsection{Path Analysis with Multiple Regressions}

Based on Table 3, it was found that almost all of the criteria were met to continue on the path analysis. The significance value of the correlation between illness representation and avoidant coping, approach coping and HRQoL, and avoidant coping and HRQoL respectively were 0.021 ( $p<0.05), 0.003(\mathrm{p}<0.05)$ and $0.016(\mathrm{p}<0.05$,). The three significance values indicate that the criteria for continuing on the path analysis have been met. However, one of the criteria was not met in the correlation between illness representations and approach coping with a significance value of $0.823(\mathrm{p}>0.05)$.

Based on the results in Table 4, to find out more about the effect of the approach coping as a mediator, analysis was carried out using SPSS AMOS, and the direct effect values for illness representations and approach coping on HRQoL were 0.884 and 1.507 respectively, while the indirect effect values for both respectively are 0.029 and 0.000 . As previously explained, to see the role of mediation, the value of the indirect effect needs to be greater than the direct effect. However, in this case, it is seen that the direct effect value of the coping approach is greater than the indirect effect value $(1.507>0.000)$. This indicates that the coping approach has no mediating effect on illness representations on HRQoL. 
Table 1. Socio-demography of participants and descriptive statistics of variables $(n=44)$

\section{Variable}

\section{Mean (SD)}

\section{Gender}

\begin{tabular}{lcc}
\hline Men & & 39 \\
\hline Women & $24.68(5.533)$ & $20-40$ \\
\hline Age & & 61 \\
\hline Marital Status & & 80 \\
\hline Single & 63.27 & $1-180$ \\
\hline Married & & \\
\hline Duration of Obesity & & 18 \\
\hline Criteria of Obesity & & 82 \\
\hline Obese I & & 91 \\
\hline Obese II & & 55 \\
\hline Causal of Obesity* & & 52 \\
\hline Eating Style & & \\
\hline Sleep Patterns & & \\
\hline Lifestyle & $89.12(13.789)$ & \\
\hline HRQOL & $24.68(4.936)$ & \\
\hline Physical Health & $20.39(4.775)$ & \\
\hline Psychological & $9.89(1.967)$ & \\
\hline Social Relationship & $27.45(3.879)$ & \\
\hline Environment & $45.20(7.855)$ & \\
\hline Illness Representations & $28.09(4.609)$ & \\
\hline Cognitive & $10.68(2.666)$ & \\
\hline Emotional & $6.43(2.627)$ & \\
\hline Comprehensibility & & \\
\hline Coping Strategies & $37.52(4.294)$ & \\
\hline Approach Coping & $28.02(4.762)$ & \\
\hline Avoidant Coping & & \\
\hline
\end{tabular}

SDUngthassififiegdviation; age unit = years; obesity duration unit = months; $\mathrm{HRQOL}=$ the higher the score, the better the quality $5 Q_{\text {ife; }}$ illness representations $=$ the higher the score, the more threatening the individual perceives his illness; unclassified = the participant cannot be described into the approach or avoidant coping through the grouping system.

* accumulation of the most frequent answers (each participant fills in a maximum of three causes)

Table 2. Analysis results of effect of illness representations on HRQoL

\begin{tabular}{|c|c|c|c|c|}
\hline Dependent Variable & $\mathbf{R}^{2}$ & $\beta$ & Sig. & Independent Variable \\
\hline HRQoL & 0.228 & -0.85 & $0.001 * *$ & Illness Representations \\
\hline Physical health & 0.286 & -0.534 & $0.000 * *$ & \multirow{4}{*}{ Comprehensibility } \\
\hline Psychological & 0.276 & -0.525 & $0.000 * *$ & \\
\hline Social relationship & 0.240 & -0.490 & $0.001 * *$ & \\
\hline Environment & 0.114 & -0.337 & $0.025^{*}$ & \\
\hline
\end{tabular}


Table 3. Path analysis criteria fulfilment test results

\begin{tabular}{lccc}
\hline Variable & ANOVA (Sig.) & Coefficients (Sig.) & Annotation \\
\hline Illness Representations*Approach Coping & 0.823 & 0.823 & Not fulfilled \\
\hline Illness Representations*Avoidant Coping & 0.021 & 0.021 & Fulfilled \\
\hline Approach Coping*HRQoL & 0.003 & 0.003 & Fulfilled \\
\hline Avoidant Coping*HRQoL & 0.016 & 0.016 & Fulfilled \\
\hline
\end{tabular}

Table 4. Value of direct, indirect, and total effect of illness representations and approach coping on HRQoL based on SPSS AMOS

\begin{tabular}{lccc}
\hline Variable & Direct & Indirect & Total \\
\hline Illness Representations & -0.884 & 0.029 & -0.856 \\
\hline Approach Coping & 1.507 & 0.000 & 1.507 \\
\hline
\end{tabular}

the sign (-) indicates the effect is negative

Table 5. Multiple regression analysis results of illness representations, avoidant coping, and HRQoL

\begin{tabular}{llcc}
\hline Variable & $\mathbf{R}^{2}$ & Sig. & $\boldsymbol{\beta}$ \\
\hline Illness Representations*Avoidant Coping & 0.121 & 0.021 & 0.248 \\
\hline Illness Representations*Avoidant Coping* HRQoL & 0.272 & 0.007 (IR) & -0.400 \\
& & 0.124 (AV) & -0.223 \\
\hline
\end{tabular}

$\mathrm{IR}=$ illness representations; $\mathrm{AV}=$ avoidant coping; sign $(-)=$ negative effect

Path analysis using regression analysis yielded several results. Simple regression analysis between illness representations and avoidant coping significantly affected avoidant coping $(\mathrm{p}=0.021 ; \mathrm{p}$ $<0.05$ ). Meanwhile, based on multiple regression analysis between illness representations, avoidant coping, and HRQoL, it was found that only the effect of illness representations on avoidant coping was significant $(p=0.007 ; p<0.05)$, while the effect of avoidant coping on HRQoL was not significant $(\mathrm{p}=$ $0.124 ; \mathrm{p}>0.05)$. Although the effect of avoidant coping on HRQoL is not significant, a decision on whether or not there is a mediating effect can be obtained after processing the regression model from Table 5.

Based on Table 5, the magnitude of the influence of the variable can be seen based on the value of $\beta$. Therefore, it is found that the effect of illness representations on avoidant coping is 0.248 . The magnitude of the effect of illness representations on HRQoL can be obtained at 0.400 , and the magnitude of the effect of avoidant coping on HRQoL is 0.223. To find the value of $e$ in the modeling, it can be obtained from the results of R2. There are two values of $e$ in this model, namely $e 1$ (influence of illness representations on avoidant coping) and $e 2$ (influence of illness representations and avoidant coping on HRQoL). The values of $e 1$ and $e 2$, respectively, are 0.937 and 0.853 . Based on these results, the path modeling form in Figure $\mathrm{I}$ is obtained.

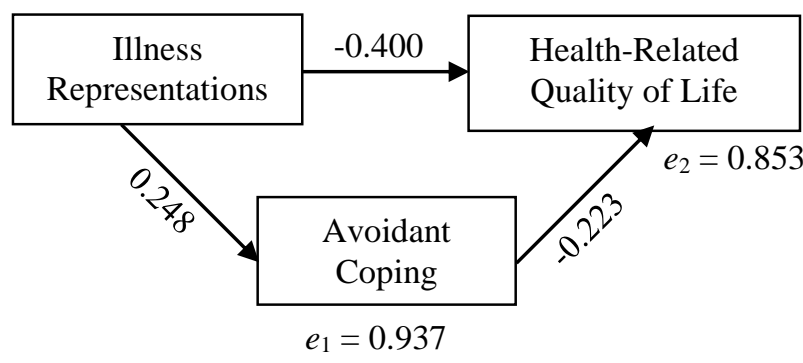

Figure 1. Path analysis with avoidant coping as mediator.

Based on Figure I, it can be seen that the direct role of illness representations on HRQoL is 0.400 . The indirect role is obtained by multiplying the value of $\beta$ of illness representations on avoidant coping and the value of $\beta$ of avoidant coping on HRQoL. Based on the multiplication values of 0.248 and 0.223 , a value of 0.05 was obtained, so it can be seen that the indirect role in this model is 0.05 . The total role in this model can be seen from the sum of the direct and indirect role values so that the total role value is 0.450 . These results indicate that the direct role is more significant than the indirect role, which indicates that there is no mediating role of avoidant coping on the effect of illness representations on HRQoL in obese patients. 


\section{DISCUSSION}

This study found a negative effect of illness representations on HRQoL; when an individual's illness representations increase, the individual's HRQoL will decrease. This shows that the more threatening disease the individual perceives, the lower their HRQoL. This finding is consistent with several previous studies. Cheng et al. [12] stated that the way individuals perceive disease can affect the quality of life of individuals both physically and mentally and can be associated negatively or positively. Meanwhile, Minshall et al. [25] stated that illness representations were negatively correlated with quality of life. This shows the consistency with the study results that the more threatening obesity is perceived, the lower the patient's HRQoL.

In general, illness representations were found to affect HRQoL. However, based on the analysis of the effect per dimension, it was found that only the comprehensibility dimension on illness representations had a significant effect on the decrease in HRQoL of obese patients. The cognitive and emotional dimensions do not significantly affect the decrease in HRQoL.

The comprehensibility dimension contains the illness coherence aspect, which describes how reasonable the illness is. It is also related to the individual's evaluation of how useful the illness representations made with the illness are[19]. This shows that the more obese people believe their obesity is happening or, the more reasonable the perceived illness representations are, the lower the HRQoL of the patient will be. The findings of this study are different from previous findings, which stated that illness coherence of disease has a positive relationship to the quality of life of individuals mentally[12], but is in line with the findings that illness coherence is negatively related to one aspect of HRQoL, that is mobility in Cushing's syndrome patients[26].

Another finding of this study shows no mediating effect of coping strategies on the effect of illness representations on HRQoL. This means that although illness representations affect HRQoL, this influence is not mediated by coping strategies; both approaches coping and avoidant coping. This shows a difference with the theoretical concept presented by Leventhal et al. [27] that the effect of illness representations on HRQoL is mediated by coping strategies. When individuals develop illness representations, this will lead individuals to perform coping strategies for the illness they suffered. After the individual implements the coping strategies, the individual will evaluate the strategic coping that has been carried out in various forms, including the individual's quality of life[11].

Based on the results of this study, it was found that neither approach coping nor avoidant coping mediates the effect of illness representations on HRQoL. This can be influenced by several things. The first is the individual's belief in illness representations that are developed. Leventhal et al. [28] stated that the success of illness representations in developing efforts to reduce the impact of the illness suffered depends on how well the individual's belief in illness representations has been developed. The second thing that might influence this result occurs because there is a tendency for individuals to think about the availability of coping resources before the individual has finished developing illness representations so that the responses given when measuring illness representations are mixed with coping evaluation[29].

Lazarus and Folkman[30] also explain that a strategy does not need to be wholly adaptive or maladaptive, but it depends on the circumstances and results from implementing this strategy. Obesity is a condition that is still rarely anticipated and considered threatening by individuals. Even so, individuals sometimes make various efforts to overcome this situation, but as a result, not all efforts have a satisfactory impact on the individual. One example is the diet effort. Even though individuals did diet or controlled eating, it was found that the obesity condition did not improve, even though the individual's weight decreased, usually it would increase again after dieting (weight cycling)[31]. It is necessary to show that the circumstances and the results obtained can affect the individual's coping process. Although this was not explored further in this study, it could be a clue for further exploration of individual perceptions of the success of coping strategies before arriving at the HRQoL evaluation.

Although no mediating effect was found, it was found that coping strategies, both approach coping and avoidant coping affected HRQoL. The approach coping affects HRQoL positively, in the sense that the more the use of the coping approach, the HRQoL will also increase. This is consistent with the findings that approach coping mechanisms are associated with positive outcomes[32]. This is also in line with the finding that state when individuals apply active coping and acceptance (type of approach coping), there is a tendency that individuals have a better quality of life[33][34].

If the coping approach positively impacts HRQoL, this is different from avoidant coping. Avoidant coping was found to negatively affect HRQoL because 
the higher the use of avoidant coping, the lower the individual's HRQoL. Various previous findings have proven that avoidant coping types tend to provide worse health outcomes[35]. In addition, it was found that the more individuals use avoidant coping to cope with their illness, the worse the individual's assessment of their health will be.

Avoidant coping is an individual's action to minimize the importance of the illness, including by not making any effort to his/her condition[36]. Obese patients are often faced with the stigma that exists in society to put individuals in a state of emotional distress so that this can influence individuals to respond to their situation with inappropriate coping strategies[37]. Obese patients found using this technique tend to have high levels of distress. This is because individuals tend to isolate themselves, do not express the emotions they feel, and lack social support, so that it can impact individuals avoiding social situations to have an impact on the individual's psychological state[38][39]. This situation then makes individuals look back at their quality of life, which in turn has an impact on a worse quality of life.

\section{CONCLUSION}

Based on the results obtained in this study, it can be concluded that there is a negative effect of illness representations on HRQoL in obese patients. When an individual's illness representations increase, the individual's HRQoL will decrease. This shows that the more threatening obesity is perceived by the individual, the lower the individual's HRQoL. This situation can occur due to several things, namely the condition of obesity experienced and the beliefs held by individuals about the disease they suffered. The percentage of the effect of illness representations on HRQoL in this study was $22.8 \%$, while the other $77.2 \%$ was influenced by other factors not explored in this study.

This research also found that the effect of illness representations on HRQoL was not mediated by coping strategies. This means that coping strategies are not appropriate mediators on the effect of illness representations on HRQoL. This can be influenced by the individual's belief in the illness representations that are developed. In addition, individual beliefs about the results obtained from the application of the applied coping strategies also play a role in determining whether or not there is a mediating effect of these coping strategies.

\section{LIMITATION}

This study explores the effect of illness representations on HRQoL in obese patients and the effect of mediating coping strategies on this effect. However, there are some limitations to this research, namely:

1. Screening of obese people is limited to BMI, which is measured directly by participants and then confirmed by researchers so that BMI calculations can be less accurate. In addition, only obese people, in general, can be explored, for other types of obesity (such as central obesity) based on a doctor's diagnosis are difficult to explore in this study.

2. The coping strategies measuring instrument used is still measuring the types of coping strategies in general and there is a possibility that obese people do not use all types of coping strategies described (while the measurement of coping strategies is based on an assessment of each aspect of coping strategies). Measurement of coping strategies that are more specific and often applied by individuals, such as the effectiveness of diet or exercise carried out, may provide a better picture of the coping strategies used by individuals.

3. This study explores more specifically the broader dimensions of illness representations (cognitive, emotional, and comprehensibility) so that it does not get a detailed explanation for the description of each aspect of these dimensions.

\section{AUTHORS' CONTRIBUTIONS}

Author 1 is conceived the idea of the research's topic and designed the analysis, collected data, contributed analysis tools, and performed the analysis. While author two and author three are supervising in all the research progress, they also conceived the idea of the research's topic and design analysis. All authors discussed the results and contributed to the final manuscript.

\section{ACKNOWLEDGMENTS}

We thank all the participants who have agreed to participate in this study fully. We thank Umniyah Saleh, S.Psi., M.Psi., Psikolog, and Dr. Ichlas Nanang Affandy, S.Psi., MA, for guidance and comments on the manuscript. This work was supported by Psychology Department, Medical Faculty, Hasanuddin University and was done under the ethical 
code of psychology from Himpunan Psikologi Indonesia (HIMPSI).

\section{REFERENCES}

[1] World Health Organization. (2020). Obesity and overweight. Retrieved on May 7th, 2020 from https://www.who.int/news-room/factsheets/detail/obesity-and-overweight

[2] Badan Penelitian dan Pengembangan Kesehatan Kementerian Kesehatan Republik Indonesia, Hasil utama Riskesdas Tahun 2018, Kementerian Kesehatan Republik Indonesia, Jakarta, 2018.

[3] C. D. Engelsen, R. C. Vos, M. Rijken, \& G. E. H. M. Rutten, Comparison of perceptions of obesity among adults with central obesity with and without additional cardiometabolic risk factors and among those who were formally obese, 3 years after screening for central obesity, BMC Public Health, 2015, 15, pp. 1-9, Doi: $10.1186 / \mathrm{s} 12889-015-2544-1$

[4] D. A. Williamson, \& P. M. O'Neil. Obesity and quality of life, in G. A. Bray and C. Bouchard (2nd ed.), Handbook of Obesity: Etiology and Pathophysiology, Marcel Dekker, New York, 2014.

[5] World Health Organization. WHOQOL user manual: Revised version, Division of Mental Health and Substance Abuse, Geneva, 2012.

[6] U. Larsson, \& E. Mattsson, Perceived disability and observed functional limitations in obese women, International Journal of Obesity, 25(11), 2001, $\mathrm{pp}$. 1705-1712,

Doi: $10.1038 /$ sj.ijo.0801805

[7] S. E. Jackson, R. J. Beeken, \& J. Wardle, Obesity, perceived weight discrimination, and psychological well-being in older adults in England, Obesity, 23(5), 2015, pp. 1105-1111, Doi: $10.1002 /$ oby.21052

[8] C. C. Wee, R. B. Davis, S. Chiodi, K. W. Huskey, \& M. B. Hamel, Sex, race, and the adverse effects of social stigma vs other quality of life factors among primary care patients with moderate to severe obesity, J Gen Intern Med, 30(2), 2015, pp. 229-235, Doi: 10.1007/s11606014-3041-4

[9] H. Leventhal, J. Yu, \& E. A. Leventhal, Illness behavior, International Encyclopedia of the
Social and Behavioral Sciences (2nd ed.), 11, 2015, pp. 596-602.

[10] H. Leventhal, I. Brissette, \& E. A. Leventhal, The common-sense model of self-regulation of health and illness, in L. Cameron and H. Leventhal (1st ed.), The Self-Regulation of Health and Illness Behavior. Routledge, London, 2003.

[11] K. K. Browning, M. E. Wewers, A. K. Ferketich, G. A. Otterson, \& M. R. Reynolds, The selfregulation model of illness applied to smoking behavior in lung cancer, Cancer Nursing, 32(4), 2009, pp. 15-25, Doi: 10.1097/NCC.0000000000000579

[12] C. Cheng, C. Y. Yang, K. Inder, \& S. W. C. Chan, Illness perceptions, coping strategies, and quality of life in people with multiple chronic conditions, Jurnal of Nursing Scholarship, 2020, pp. 1-10, Doi: 10.1111/jnu. 12540

[13] C. O. Gregory, H. M. Blanck, C. Gillespie, L. M. Maynard, \& M. K. Serdula, Perceived health risk of excess body weight among overweight and obese men and women: Differences by sex. Preventive Medicine, 47, 2008, pp. 46-52, Doi: 10.1016/j.ypmed.2008.01.008

[14] K. R. Fontaine, Health-related quality of life among obese subgroups, Obesity Research, 10(8), 2002, pp. 854-855, Doi: 10.1038/oby.2002.115

[15] G. W. Health, \& D. W. Brown, Recommended levels of physical activity and health-related quality of life among overweight and obese adults in the United States 2005, Journal of Physical Activity and Health, 6, 2009, pp. 403411, Doi: 10.1123/jpah.6.4.403

[16] World Health Organization, WHOQOL Measuring Quality of Life, Division of Mental Health and Prevention of Substance Abuse, Geneva, 1997.

[17] S. N. Renaldi, Pemaknaan dukungan sosial dan health-related quality of life terhadap survivor kanker serviks, Undergraduate Thesis, Hasanuddin University, Makassar, 2009.

[18] E. Broadbent, K. J. Petrie, J. Main, \& J. Weinman, The brief illness perception questionnaire, Journal of Psychosomatic Research, 60, 2006, pp. 631-637, Doi: 10.1016/j.jpsychores.2005.10.020 
[19] R. Moss-Morris, J. Weinman, K. J. Petrie, R. Horne, L. D. Cameron, \& D. Buick, The revised illness perception questionnaire (IPQ-R), Psychology and Health, 17(1), 2002, pp. 1-16, Doi: 10.1080/08870440290001494

[20] S. Indrayana, \& S. Y. Fang, Validitas dan reliabilitas The Brief Illness Perception Questionnaire versi Bahasa Indonesia pada pasien diabetes mellitus, Dinamika Kesehatan Jurnal Kebidanan dan Keperawatan, 10(1), 2019, pp. 361-368, Doi: 10.33859/dksm.v10i1.397

[21] C. S. Carver, You want to measure coping but your protocols too long: Consider the Brief COPE, International Journal of Behavioral Medicine, 4(1), 1997, pp. 92-100, Doi: 10.1207/s15327558ijbm0401_6

[22] D. Clark-carter, Quantitative psychological research: The complete student's companion (4th ed.), Routledge, New York 2019.

[23] S. Urbayatun, \& W. Widhiarso, Variabel mediator dan moderator dalam penelitian psikologi kesehatan masyarakat, Jurnal Psikologi, 39(2), 2012, pp. 180-188, Doi: $10.22146 /$ jpsi.6985

[24] R. M. Baron, \& D. A. Kenny, The moderatormediator variable distinction in social psychological research: Conceptual, strategic, and statistical considerations, Journal of Personality and Social Psychology, 51(6), 1986, pp. 1173-1182, Doi: 10.1037/00223514.51.6.1173

[25] C. Minshall, C. F. Ski, P. Apputhural, D. R. Thompson, D. J. Castle, Z. Jenkins, \& S. R. Knowles, Exploring the impact of illness perceptions, self-efficacy, coping strategies, and psychological distress on quality of life in a poststroke cohort, Journal of Clinical Psychology in Medical Settings, 2020, pp. 1-7. Doi:10.1007/s10880-020-09700-0

[26] J. Tiemensma, A. A. Kaptein, A. M. Pereira, J. W. A. Smit, J. A. Romijn, \& N. R. Bierma, Negative illness perceptions are associated with impaired quality of life in patients after long-term remission of ushing's syndrome, European Journal of Endocrinology, 165, 2011, pp.527535, Doi: 10.1530/EJE-11-0307

[27] H. Leventhal, D. Meyer, \& D. Nerenz, The common sense representation of illness danger, in S. Rachman (Ed.), Contributions to Medical
Psychology, Pergamon Press, New York, 1980, pp.17-30.

[28] H. Leventhal, J. Weinman, E. A. Leventhal, \& L. A. Phillips, Health psychology: The search for pathways between behavior and health, Annu Rev Psychol, 59, 2008, pp. 477-505, Doi: 10.1146/annurev.psych.59.103006.093643

[29] M. Dempster, N. K. McCorry, \& D. Howell, Illness perceptions and coping in physical health conditions: A meta-analysis, Journal of Psychosomatic Research, 2015, pp. 1-36, Doi: 10.1016/j.jpsychores.2015.10.006

[30] R. S. Lazarus, \& S. Folkman, Stress, appraisal, and coping, Springer Publishing Company, New York, 1984.

[31] K. Keller, Encyclopedia of Obesity, Sage Publications, California, 2008.

[32] P. Awasthi, \& R. C. Mishra, Illness beliefs and coping strategies of diabetic women, Psychol Stud, 56(2), 2011, pp. 176-184, Doi: 10.1007/s12646-011-0074-1

[33] V. LoBuono, F. Corallo, P. Bramanti, \& S. Marino, Coping strategies and health-related quality of life after stroke, Journal of Health Psychology, 2015, pp. 1-13, Doi: $10.1177 / 1359105315595117$

[34] M. L. Elfstrom, A. Ryden, M. Kreuter, C. Taft, \& M. Sullivan, Relations between coping strategies and health-related quality of life in patients with spinal cord lesion, J Rehabil Med, 37, 2005, pp. 9-16, Doi: $10.1080 / 16501970410034414$

[35] E. A. Bell, The relationship between illness representations, avoidant coping, and health outcomes in people with ongoing symptoms of chronic illness, UNF Graduate Theses and Dissertations, University of North Florida, 2015.

[36] J. Ogden, Health psychology: A textbook (3rd ed.), Open University Press, Berkshire, 2004.

[37] V. H. Taylor, M. Forhan, S. N. Vigod, R. S. McIntyre, \& K. M. Morrison, The impact of obesity on quality of life, Best Practice \& Research Clinical Endocrinology \& Metabolism, 27, 2013, pp. 139-146, Doi: 10.1016/j.beem.2013.04.004 
[38] A. Myers, \& J. C. Rosen, Obesity stigmatization and coping: relation to mental health symptoms, body image, and self-esteem. International Journal of Obesity, 23(3), 1999, pp. 221-230. Doi: $10.1038 /$ sj.ijo.0800765

[39] R. Puhl, \& K. D. Brownell, Ways of coping with obesity stigma: review and conceptual analysis, Eating Behaviors, Vol.4, 2003, pp. 53-78, Doi: 10.1016/s1471-0153(02)00096-x 